\title{
Extensive Vascular Calcification in Association with Juvenile Rheumatoid Arthritis and Amyloidosis
}

\author{
M. MCC. REID and T. F. FANNIN \\ From the Royal Belfast Hospital for Sick Children; and the Nuffield Department of Child Health and the \\ Department of Pathology, The Queen's University of Belfast
}

Amyloidosis is an uncommon complication of juvenile rheumatoid arthritis. Forsyth (1960) described such a case, where, in additon, there was small vessel calcification. The following report of a similar case is of interest in view of the extensive arterial calcification, amyloidosis, and arteritis seen at necropsy.

\section{Case History}

A.D. was a normal boy until the age of $2 \frac{1}{2}$ years when he was admitted to hospital with a history of one week's anorexia, pyrexia, difficulty in walking, and generalized pains. There was a rash over the abdomen and pain in his hip and knee joints. The only laboratory findings of note were a white cell count of 23,000 (polymorphs $75 \%$ ) and $\mathrm{Hb} 9.6 \mathrm{~g} . / 100 \mathrm{ml}$. He was treated with penicillin and streptomycin, made a good recovery, and was discharged after one month in hospital.

When aged $2 \frac{3}{4}$ years the fever and generalized pains recurred and he was again admitted to hospital. He was thin with painful swellings of both wrists, and reduced cervical spine movement; and had splenomegaly, generalized lymphadenopathy, and a faint erythematous rash over the trunk and hands. Temperature $40 \cdot 5^{\circ} \mathrm{C}$.

ESR $58 \mathrm{~mm} . / 1 \mathrm{hr}$.; Hb 8.9 g./100 ml.; WBC 48,000, with $86 \%$ polymorphs; serum protein $6.6 \%$, albumin $2.9 \%$, globulin $3.7 \%$; urine, albumin + . $X$-ray of wrist showed slight decalcification.

He was given soluble aspirin for one month, but then relapsed and was treated with prednisone, $20 \mathrm{mg}$. $/$ day, with marked improvement, and he was eventually discharged when aged $3 \frac{1}{2}$ years on no treatment.

A month later there was a recurrence of the arthralgia, rash, and pyrexia. Again there was a poor response to salicylate treatment, and gold therapy was started, but after a single injection of $1 \mathrm{mg}$. soluble aurothiomalate he became jaundiced: serum alkaline phosphatase was then $106 \mathrm{KA}$ units, SGOT 160 units, and SGPT 175 units.

No further gold was given and prednisone was restarted. Aged 4 years 1 month he was discharged on $5 \mathrm{mg}$. prednisone twice weekly, being fully mobile and having no joint pains. He remained well, and steroid therapy was stopped a year later.

Received March 25, 1968.
When aged 81 years he developed jaundice at the same time as his mother and two sibs. In addition, he had abdominal pain and a generalized morbilliform rash. He was transferred to hospital as he was vomiting and had developed abdominal swelling. On examination he was thin and jaundiced. The large joints were swollen and tender. There was marked ascites and hepatosplenomegaly.

Hb 12.9 g. $/ 100 \mathrm{ml}$.; WBC 20,000 , polymorphs $71 \%$; platelets 746,000 per cu.mm.; serum protein $3.9 \%$; albumin $1.04 \% ; \quad \alpha_{1}$-globulin $0.36 \% ; \quad \alpha_{2}$-globulin $0.67 \% ; \beta$-globulin $0.75 \% ; \gamma$-globulin $1.08 \%$; blood urea $82 \mathrm{mg} . / 100 \mathrm{ml}$. rising to $116 \mathrm{mg} . / 100 \mathrm{ml}$. over the next 7 days; blood ammonia $270 \mu \mathrm{g} . / 100 \mathrm{ml}$. (normal 40-70); LE-cells not seen; latex-fixation test negative; leptospiral agglutination negative; bilirubin $6.8 \mathrm{mg} . / 100$ ml.; pseudocholinesterase 35 units; SGOT 720 units; SGPT 630 units; alkaline phosphatase $54 \mathrm{KA}$ units. Urine, protein ++ . Prothrombin time $34-52 \%$. Congo red test $40 \%$ retention after one hour.

Treatment. A low protein-high carbohydrate diet, and oral neomycin, prednisone, aldactone, chlorothiazide, and potassium chloride were given in view of hepatic failure, exacerbation of rheumatoid arthritis, and fluid retention.

He vomited blood on several occasions, and barium swallow suggested early oesophageal varices. Extensive bruising now appeared and he required analgesics for relief of retrosternal and upper abdominal pain (which, in retrospect, was probably angina). There was some remission of the joint pains and 4 months after his admission he was able to walk with some assistance. Two weeks later he had a generalized convulsion. Blood pressure was $200 / 140 \mathrm{~mm}$. $\mathrm{Hg}$, blood urea 175 mg. $/ 100 \mathrm{ml}$; acid-base estimation showed a severe metabolic and respiratory acidosis; serum calcium $6 \cdot 2$ mg./100 ml.; serum phosphorus $11.9 \mathrm{mg} . / 100 \mathrm{ml}$. He died 2 days later aged $8 \frac{1}{2}$ years.

Necropsy. The following are the relevant findings. In the heart the atrial walls were rendered rigid by hard yellow-green subendocardial plaques of calcified material (Fig. 1). The coronary arteries were also rigid and calcified, and several branches, including the anterior descending and the left circumflex, were occluded. Histologically, deposits of calcium were seen in the 


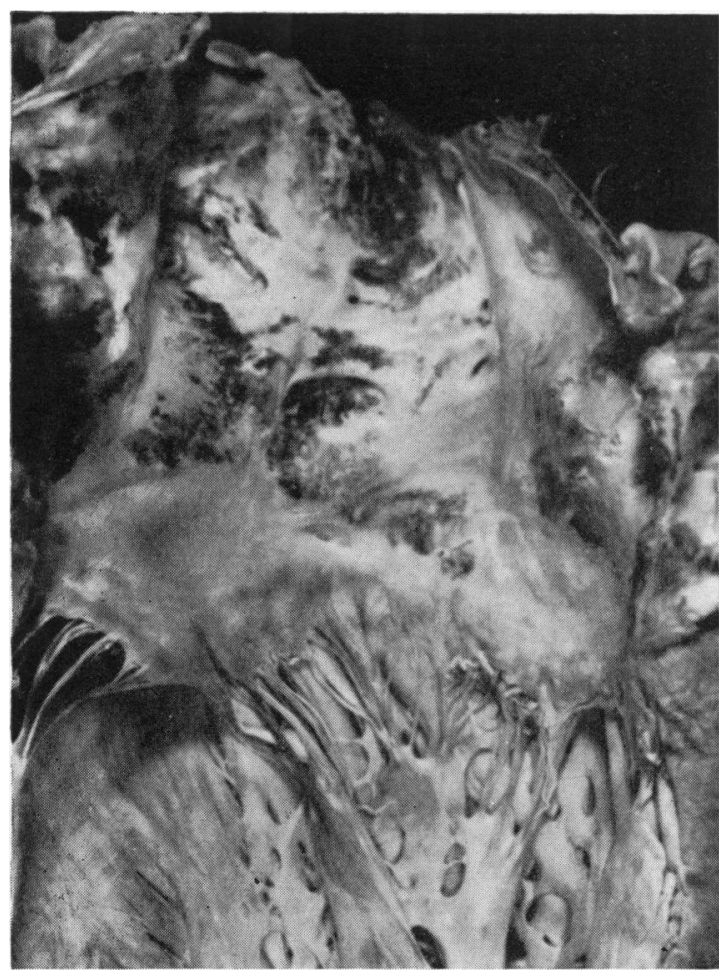

Fig. 1.-Heart-the left atrium, mitral valve, and base of the left ventricle are exposed. Dark flecks of calcific material cover the endocardium of the atrium and coalesce to form large areas. The mitral valve cusps are not affected. (Approx. $\times 2 \frac{1}{2}$.)

subendocardial tissues and small areas of fibrosis were present in the myocardium.

In the vascular system the aorta showed slight fatty streaking but no calcification. However, all the major branches were rigid and calcified, some of the smaller vessels being almost occluded. Very marked medial calcification was seen in the coronary (Fig. 2), mesenteric, coeliac, thyroid, hepatic, splenic, renal, and intramuscular arteries. The internal elastic lamina was fragmented and reduplicated, and subintimal fibrosis was marked. Occlusions were seen in the small branches of the coronary arteries (Fig. 2). The arterioles of the liver, heart, spleen, adrenal, and kidneys had a deposit of hyaline material in their walls giving a positive reaction with Congo red, suggestive of amyloid (Fig. 3). Post-mortem $x$-ray of the right kidney demonstrated the extent of the vascular calcification (Fig. 4).

In the endocrine system the parathyroid and pituitary glands were normal, but the other glands showed marked amyloid infiltration.

Examination of the ribs showed decreased density, and at the costochondral junction normal cartilage maturation was lost, only a few shrunken irregular cartilage cells being found (Fig. 5).

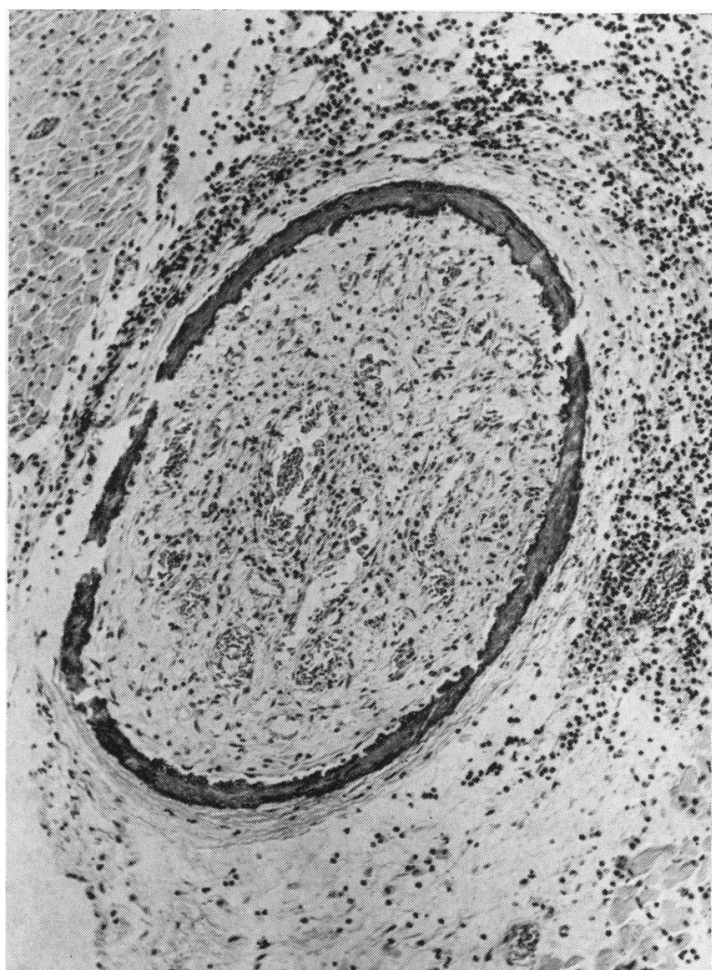

FIG. 2.-Anterior descending coronary artery-the rim of calcific material is deposited around the media. The lumen has been occluded by fibrous tissue and recanalization has occurred by means of numerous small thin-walled vascular channels. $(\times 97$.

Pannus from the knee joint showed moderate chronic inflammatory changes with infiltration of the vascular villous projections by lymphocytes, plasma cells, and monocytes.

\section{Discussion}

Several surveys have been carried out into the course and prognosis of juvenile rheumatoid arthritis (Ansell and Bywaters, 1956; Schlesinger et al., 1961). Amyloidosis is a rare complication, estimates varying from 1 in 100 cases (Schlesinger et al., 1961) to 11 in 316 (Ansell and Bywaters, 1956). This is in contrast to adult rheumatoid arthritis in which the incidence of amyloid ranges from $4 \%$ (Fearnley and Lackner, 1955) to $15 \%$ (Missen and Taylor, 1956), and even as high as $60 \%$ (Teilum and Lindahl, 1954). Amyloid deposition was marked in the present case, in particular in the kidney where there was virtual replacement of all glomeruli. The prognosis is poor and survival is said to be less than 5 years from the diagnosis (Kenney and Calkins, 1965). 


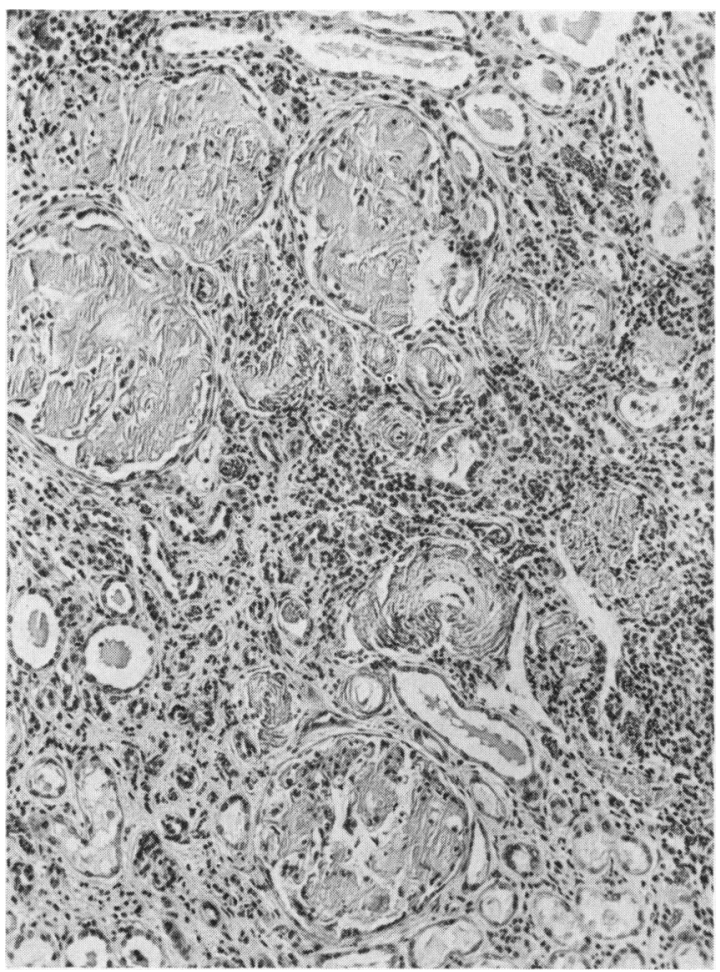

Fig. 3.-Kidney-the normal cellular architecture of the glomeruli is replaced by a hyaline mass of amyloid. $A$ similar deposit is noted in the small arteries. Tubules are dilated and many contain casts. A chronic inflammatory cellular infiltrate is present in the interstitial tissues. $(\times 88$.

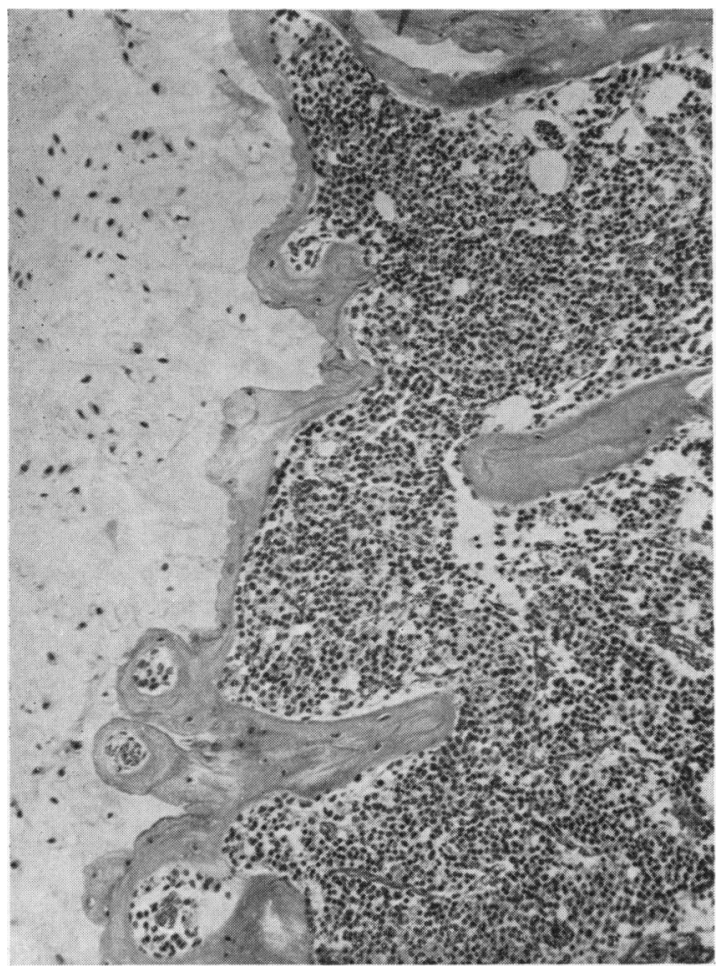

FIG. 4.-Kidney-post-mortem $\mathrm{x}$-ray. The renal arteries are outlined by a white line of calcific material.

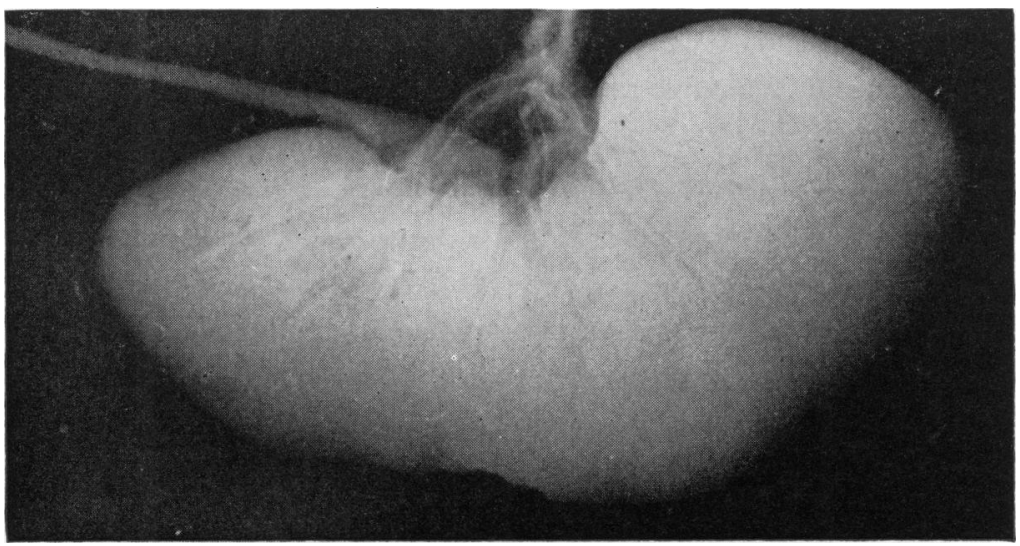

Fig. 5.-Rib-the thickness of the epiphysial plate of cartilage is much reduced and the cartilage cells are small, atrophic, and inactive. The cortical plate of bone is thin and has a scalloped edge; resorption lines are apparent. The lamellae of new bone are reduced in both number and size and resorption lines are prominent. $(\times 114$. 
Steroid therapy in amyloid disease has been said to cause worsening of the condition in experimental animals (Teilum, 1952). However, other authors have failed to confirm this (Cohen, Calkins, and Franklin Mullinax, 1962). Furthermore, C. C. Forsyth (1960; personal communication, 1966) has described a case of juvenile rheumatoid arthritis complicated by amyloidosis and small vessel calcification in which treatment with prednisolone produced regression of the amyloid disease. Equally intriguing in that case was the undoubted diminution in vascular calcification and the recalcification of the skeleton which followed the prednisolone treatment.

Vascular changes have been described in many cases of adult rheumatoid disease and may be divided as follows: (1) subacute lesions of small vessels, in myocardium, muscles and nerve sheaths (Cruickshank, 1954); (2) severe necrotizing arteritis indistinguishable from polyarteritis nodosa (Ball, 1954); and (3) bland intimal proliferation usually of digital vessels, which may progress to an obliterative endarteritis (Bywaters, 1957). This third type is similar to that seen in the present case.

Arterial calcification in childhood, though uncommon, has been described by many authors in a variety of disorders such as syphilis, idiopathic hypercalcaemia, and hypervitaminosis D (Baggenstoss and Keith, 1941; Stryker, 1946; Moran and Steiner, 1962). However, in these conditions it usually involves the coronary arteries only, with death in the first 6 months of life. Calcification of vessels in juvenile rheumatoid arthritis has been reported by Forsyth (1960), but not to the degree observed in this case. Hypervitaminosis $\mathrm{D}$ and idiopathic hypercalcaemia were excluded as causes in this case.

In considering the sequence of events in our patient it appears that this child's juvenile rheumatoid arthritis was complicated by a widespread arteritis of the third type described by Bywaters (1957). The damaged blood vessels formed a suitable site for the deposition of the liberated calcium made available by prolonged bed-rest and corticosteroid therapy. The blood vessels were also heavily involved by amyloid that also caused the progressive renal failure, proteinuria, and metabolic acidosis.

\section{Summary}

The clinical and pathological findings are presented of a case of juvenile rheumatoid arthritis, complicated by amyloid disease, widespread vascular calcification, and arteritis, with marked narrowing of arteries and occlusions within the coronary system.

We wish to thank Professor Sir John H. Biggart for allowing us to study this patient; and Professor I. J. Carré and $\mathrm{Dr}$. H. Jones for their helpful advice in the preparation of this paper.

\section{REFRRENCES}

Ansell, B. M., and Bywaters, E. G. L. (1956). Growth in Still's disease. Ann. rheum. Dis., 15, 295.

Baggenstoss, A. H., and Keith, H. M. (1941). Calcification of the arteries of an infant. F. Pediat., 18, 95.

Ball, J. (1954). Rheumatoid arthritis and polyarteritis nodosa. Ann. rheum. Dis., 13, 277.

Bywaters, E. G. L. (1957). Peripheral vascular obstruction in rheumatoid arthritis and its relationship to other vascular lesions. ibid., 16, 84.

Cohen, A. S., Calkins, E., and Franklin Mullinax, P. (1962). Studies in experimental amyloidosis. III. The effect of cortisone administration on the incidence of casein-induced amyloidosis in the rabbit. Arch. intern. Med., 110, 569.

Cruickshank, B. (1954). The arteritis of rheumatoid arthritis. Ann. rheum. Dis., 13, 136.

Fearnley, G. R., and Lackner, R. (1955). Amyloidosis in rheumatoid arthritis, and significance of 'unexplained' albuminuria. Brit. med.f., 1, 1129.

Forsyth, C. C. (1960). Calcification of the digital vessels in a child with rheumatoid arthritis. Arch. Dis. Childh., 35, 296.

Kenney, J. D., and Calkins, E. (1965). Clinical aspects of amyloidosis. In Progress in Clinical Rheumatology, p. 281. Ed. by A. St. J. Dixon. Churchill, London.

Missen, G. A. K., and Taylor, J. D. (1956). Amyloidosis in rheumatoid arthritis. F. Path. Bact., 71, 179.

Moran, J. J., and Steiner, G. C. (1962). Idiopathic arterial calcification in a 5-year-old child. A case report. Amer. f. clin. Path., 37, 521.

Schlesinger, B. E., Forsyth, C. C., White, R. H. R., Smellie, J. M., and Stroud, C. E. (1961). Observations on the clinical course and treatment of one hundred cases of Still's disease. Arch. Dis. Childh., 36, 65.

Stryker, W. A. (1946). Arterial calcification in infancy with special reference to the coronary arteries. Amer. F. Path., 22, 1007.

Teilum, G. (1952). Cortisone-ascorbic acid interaction and the pathogenesis of amyloidosis; mechanism of action of cortisone on mesenchymal tissue. Ann. rheum. Dis., 11, 119.

, and Lindahl, A. (1954). Frequency and significance of amyloid changes in rheumatoid arthritis. Acta med. scand., $149,449$. 